\title{
Clinical experiences with ultrasound-guided suprazygomatic maxillary nerve block in zygomatic implants surgery: a new indication
}

Molins G. MD, MSc.1

Valls-Ontañón A. MD, MSc, DMD, PhD.2

(1) Anestalia - Centro Médico Teknon. Barcelona. Spain

Masiá J. MD.2

(2) Instituto Maxilofacial - Centro Médico Teknon. Barcelona. Spain

De Nadal M. MD, PhD.3

Hernández-Alfaro F. MD, DMD, PhD.2

(3) Hospital Vall d'Hebrón. Barcelona. Spain

Zygomatic implant surgery (ZIS) is indicated for the rehabilitation of the severe atrophic maxilla. Anesthetic management of these patients is a challenge. For pain control, a multimodal approach is recommended, and loco-regional-anesthesia techniques (LRAT) are an essential pillar. Researchers propose bilateral blockade of the maxillary nerve (BBMN) by ultrasound-guided suprazigomatic-route for ZIS for better pain control. In this clinical trial, after ethical committee approval patients were randomly assigned to 2groups to receive (study group) or not (control group) the BBMN (4mI Ropivacaine $0.5 \%$ ) together with local infiltration with Lidocaine $(10 \mathrm{ml}$ Lidocaine2\%) and general anesthesia. The main objective was the consumption of opioids. Pain, postoperative nausea-vomiting (PONV) and complications derived from BBMN were also recorded. The researchers present the preliminary results of 9 patients. Patients who received $B B M N$ presented better results in terms of: lower intraoperative opiods consumption $(p=0.016)$, lower rate of patients who demanded methadone $(100 \%$ control vs $20 \%$ study, $p=0.048)$ and lower dose of methadone administered ( $3 \mathrm{mg}$ control vs $0 \mathrm{mg}$ study, $p=0.016$ ) at 2hours postoperatively, lower level of pain at any time of the first 8hours postoperatively $(p=0.016)$, and lower incidence of PONV (75\% control vs $0 \%$ study, $\mathrm{p}=0.048$ ).
No complications derived from the BBMN were reported.

The results obtained suggest that the BBMN is a promising LRAT to decrease opioid consumption and greater patient comfort for ZIS. The small size of the sample prevents generalization, and may involve risks of overinterpretation and publication bias. Larger studies need to be conducted to corroborate the efficacy of this new indication.
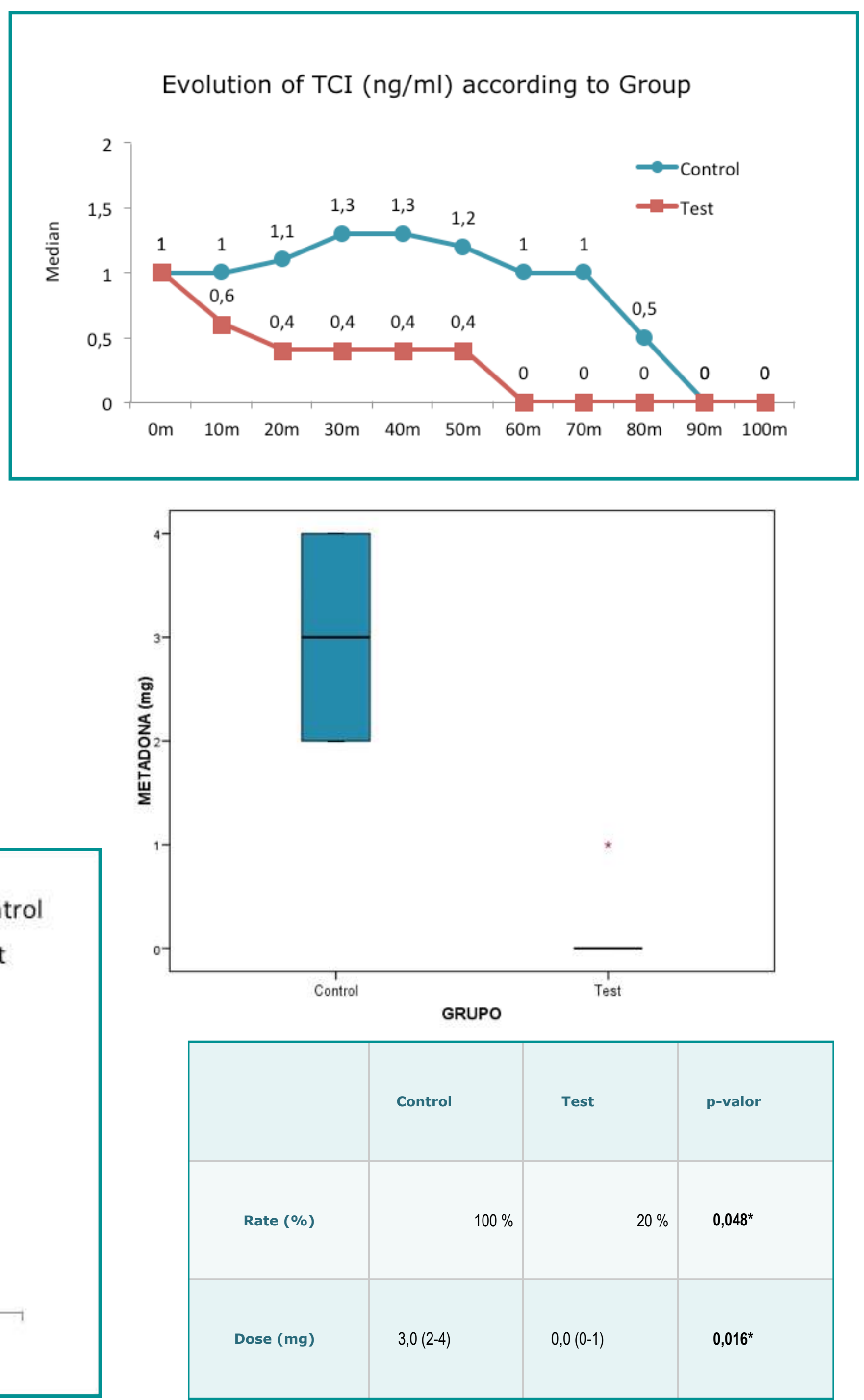

REFERENCES:

1. Chiono J, Raux O, Bringuier S, Pharm D, Sola C, Bigorre M, Capdevila X, Dadure C. Bilateral Suprazygomatic Maxillary Nerve Block for Cleft Palate Repair in Children. Anesthesiology 2014;120:1362-9.

2. Bouzinac A, Tournier J-J, Delbos A. Ultrasound-guided maxillary nerve block in adults: feasibility and efficiency for postoperative analgesia after maxillary osteotomy. Minerva Anest 2014;80(7):860-1.

3. Echaniz G, De Miguel M, Merritt G, Sierra P, Bora P, Borah N, Ciarallo C, de Nadal M, Ing RJ, Bosenberg A. Bilateral suprazygomatic maxillary nerve blocks vs. infraorbital and palatine nerve blocks in cleft lip and palate repair: A double-blind, randomised study. Eur J Anaesthesiol. 2019;36(1):40-47. 